\title{
Nuclear magnetic resonance (NMR) tomographic imaging for popliteal cysts in rheumatoid arthritis
}

\author{
R. G. HULL, ${ }^{1}$ J.A. N. RENNIE, ${ }^{1}$ C. J. EASTMOND, ${ }^{1}$ \\ J.M.S. HUTCHISON ${ }^{2}$ AND F. W. SMITH ${ }^{3}$ \\ From the ${ }^{1}$ Department of Rheumatology, City Hospital, Aberdeen, the ${ }^{2}$ Department of Biomedical Physics and \\ Bio-Engineering, University of Aberdeen, and the ${ }^{3}$ Department of Nuclear Medicine, Aberdeen Royal \\ Infirmary
}

SUMMARY The ability of nuclear magnetic resonance (NMR) tomographic imaging to show a change in proton spin-lattice relaxation time $\left(\mathrm{T}_{1}\right.$ value $)$ in the joints of patients with rheumatoid arthritis before and after treatment with intra-articular steroid has been assessed. Six patients with seropositive rheumatoid arthritis and clinical evidence of a popliteal cyst were examined by both NMR tomography and arthrography. In all cases the presence of active rheumatoid arthritis was shown by an increase in the $T_{1}$ values of the synovium of the joints. After arthrography a consistent but small rise in $T_{1}$ value was noted which fell to below the initial reading after treatment by intra-articular injection of an anti-inflammatory agent. In all cases the presence of the popliteal cyst was clearly shown by both NMR tomography and arthrography. The findings indicate that NMR tomography provides a sensitive method for the demonstration of inflammatory joint disease, popliteal cysts, and possibly for monitoring response to therapy.

Nuclear magnetic resonance (NMR) tomographic imaging is a new noninvasive diagnostic technique employing nonionising radiation which is currently being developed and evaluated at a number of centres. ${ }^{1}$ It produces images which depend on the hydrogen proton concentration in tissues and hence their water composition, unlike $x$-ray computerised tomography ( $x$-ray CT) and ultrasound, which depend on tissue density. Reports of its early clinical application indicate that it is sensitive in the demonstration of intrathoracic and intra-abdominal malignancy $^{2-5}$ and more sensitive than $x$-ray CT in the demonstration of demyelination in multiple sclerosis. ${ }^{6}$ In addition benign tumours such as haemangiomata and inflammatory conditions such as abscesses and pneumonia have recently been demonstrated by NMR.?

The NMR image is made up of different proton spin-lattice relaxation times ( $T_{1}$ values). Each tissue has its own $T_{1}$ value dependent upon the environment of the protons. The vast majority of hydrogen protons in body tissues are in water molecules. The hydrogen proton $T_{1}$ values of individual tissues are dependent upon the degree of protein binding of

Accepted for publication 26 January 1983.

Correspondence to Dr J. A. N. Rennie, Department of Rheumatology, City Hospital, Urquhart Road, Aberdeen AB2 1NG. tissue water. Tissues with a large amount of bound water such as muscle and liver have short $T_{1}$ values, and those with less, such as kidney, spleen, and blood, have longer $T_{1}$ values. The longest $T_{1}$ values are found in body fluids such as cerebrospinal fluid, urine, and ascites. ${ }^{8}$ Inflammatory lesions have raised $T_{1}$ values ${ }^{7}$ due to a high proportion of unbound water as a result of hyperaemia and associated soft tissue oedema. The purpose of the present study was to demonstrate that NMR tomography could localise areas of joint inflammation in knees and popliteal cysts and show a decrease in $T_{1}$ in response to a potent anti-inflammatory agent.

\section{Materials and methods}

Six patients with seropositive rheumatoid arthritis and clinical evidence of a popliteal or Baker's cyst were studied. Each gave informed verbal consent for NMR examination and arthrography. NMR tomograms of the knees were performed on day one, 2 sections being made, one through the head of the fibula and the other $2 \mathrm{~cm}$ above. On day 2 arthrography of the knee was performed under radiological control. $20 \mathrm{ml}$ of synovial fluid was withdrawn through a $19 \mathrm{~g}$ needle and replaced with $20 \mathrm{ml}$ of $x$-ray contrast medium (Urografin $410 \mathrm{M}$ ). The knee 


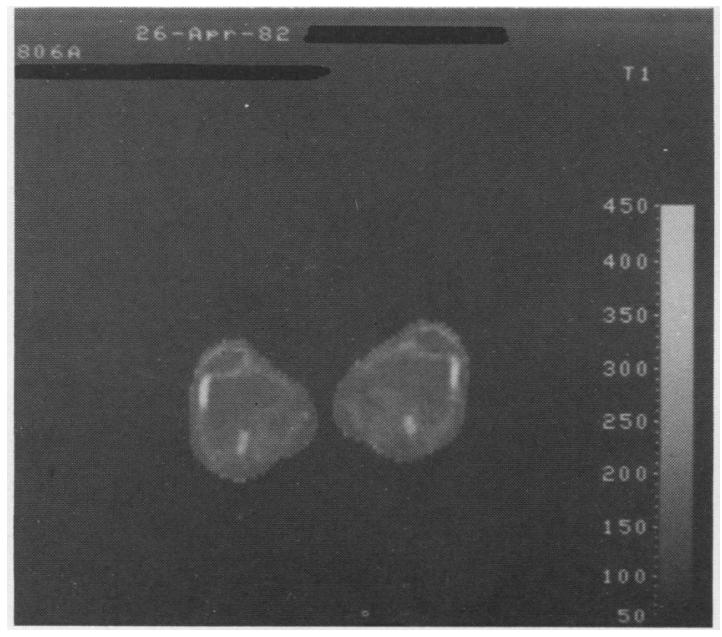

Fig. 1 NMR $T_{1}$ image of normal knees. The image of the right knee is on the left and vice-versa. The anterior surface of the knees is at the top of the image.

was exercised actively until the contrast was dispersed throughout the synovial space. Anteroposterior and

- lateral radiographs were taken. Eighteen hours later on day 3 NMR imaging was repeated. Later that day $20 \mathrm{mg}$ of triamcinolone hexacetonide was injected into the joint, and a final NMR examination was performed 5 days later on day 8 .

All the NMR images were produced with the NMR imager developed at the University of Aberdeen using the 'spin-warp' method of NMR imaging, employing a 0.04 Tesla magnetic field with a resultant $1 \cdot 7 \mathrm{MHz}$ frequency for hydrogen protons..$^{9-11}$ Each

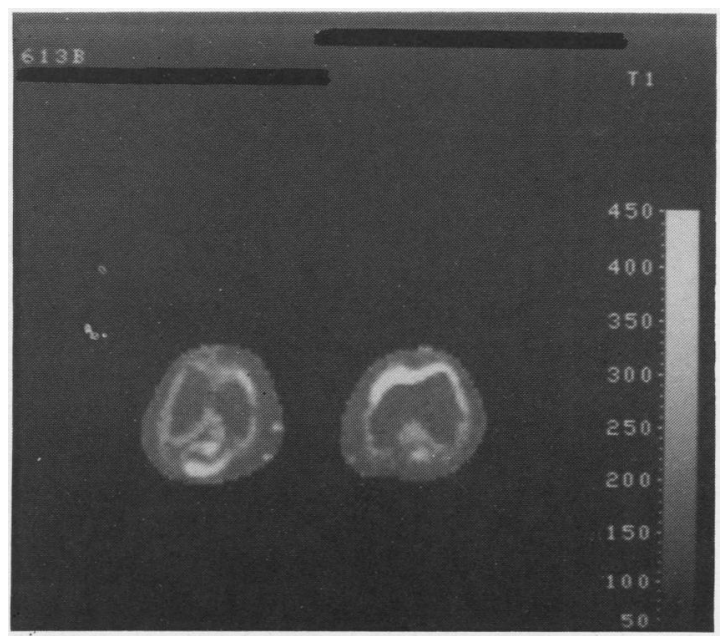

Fig. $2 N M R T_{1}$ image showing a popliteal cyst in the right knee (patient no. 1).

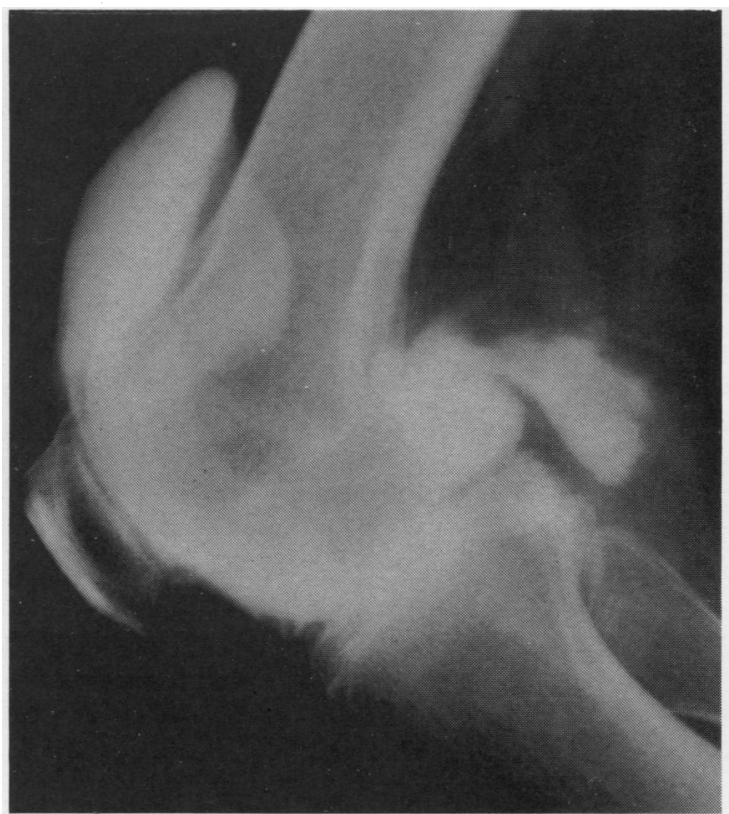

Fig. 3 Arthrogram of right knee of patient no. 1 .

section was $16 \mathrm{~mm}$ thick and produced from data collected in 4 minutes. The images are displayed in either monochrome or colour, the latter being coded in 16 colours for ease of detection of small changes in $T_{1}$ values.

\section{Results}

In the normal subject the $T_{1}$ value of the synovium of the knee joint is $180-190 \mathrm{~ms}$ (Smith, unpublished data) and the NMR tomographic appearances are characteristic (Fig. 1). The lower end of the femur is not visualised because of the lack of protons in bone resulting in a very low signal; the slightly 'wetter' cartilage and synovium showing as a light grey.

Initial $T_{1}$ values in synovium were raised in all 6

Table 1 Range of $T_{1}$ values of synovium and synovial fluid in rheumatoid arthritis. Day 1, first day of study. Day 3, 24 hours after arthrography. Day 8, 5 days after intraarticular injection of $20 \mathrm{mg}$ of triamcinolone hexacetonide

\begin{tabular}{llll}
\hline \multirow{2}{*}{ Patients } & \multicolumn{3}{l}{ Proton spin-lattice relaxation time } \\
\cline { 2 - 4 } & Day 1 & Day 2 & Day 3 \\
\hline 1 & $250-300$ & $325-400$ & $210-250$ \\
2 & $250-300$ & $375-400$ & $200-205$ \\
3 & $240-260$ & $370-390$ & $200-210$ \\
4 & $180-200$ & $210-220$ & $160-175$ \\
5 & $180-200$ & $210-220$ & $155-165$ \\
6 & $250-270$ & $375-390$ & $190-195$ \\
\hline
\end{tabular}




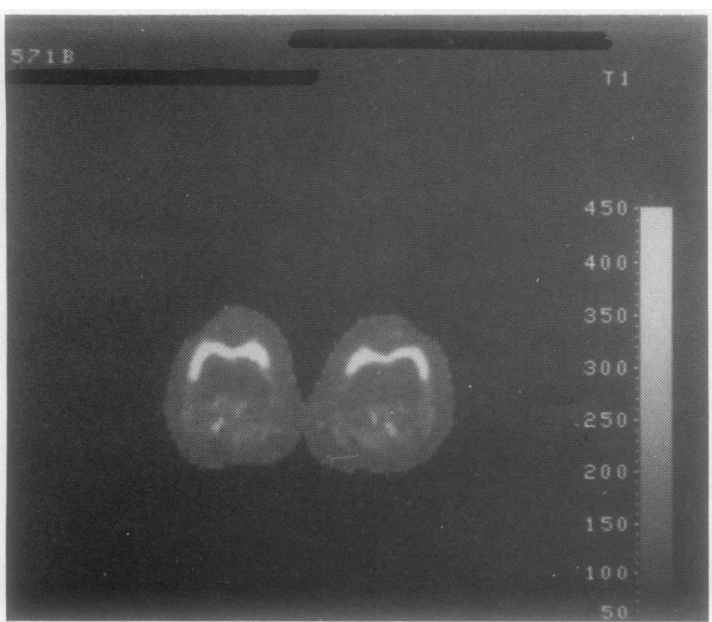

Fig. 4 NMR $T_{1}$ image of knees of patient no. 2 on day 1 showing long $T_{1}$ values (white) of the synovium of both knees.

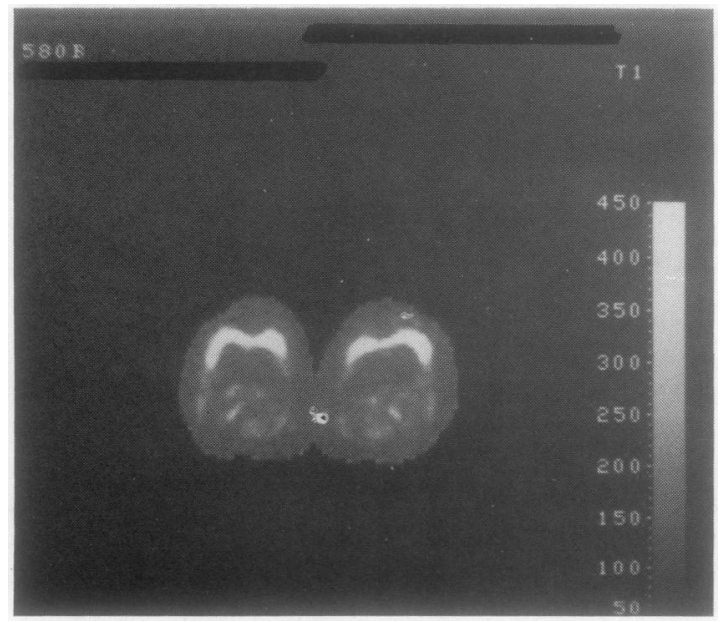

Fig. $5 N M R T_{1}$ image of patient no. 2 following arthrography of the left knee. An increase in the $T_{1}$ value is illustrated by an increase in the amount of white seen in the joint space.

patients studied. The popliteal cysts were visualised by both NMR imaging and subsequent arthrography (Figs. 2 and 3). The $T_{1}$ values for the fluid within the cysts were in the range $250-300 \mathrm{~ms}$ and were the same as that of the synovial fluid in the joint space.

After arthrography a small but definite rise in $T_{1}$ values was noted in the investigated joints (Table 1). In 5 cases bilateral involvement was present and no increase in $T_{1}$ values was observed in the knee not subject to arthrography. NMR images 5 days after

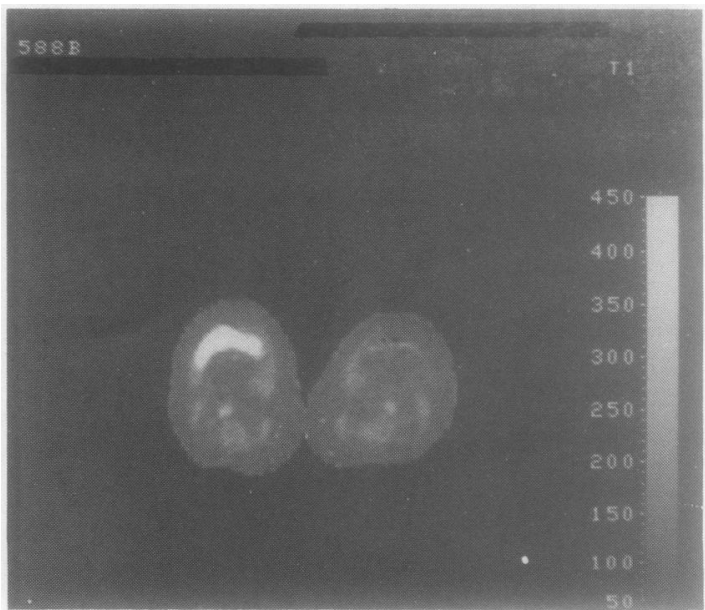

Fig. 6 NMR $T_{1}$ image of patient no. 2 five davs after intra-articular injection with triamcinolone hexacetonide illustrating the marked decrease in inflammation in the lefi knee.

the injection of the anti-inflammatory agent triamcinolone hexacetonide all showed a marked fall in $\mathrm{T}_{1}$ values in the treated joint as compared with the initial images (Table 1). A slight decrease in $T_{1}$ values was observed in the untreated knees.

These observations are illustrated in Figs. 4-6. This patient (no. 2) was a 44-year-old woman with a 4-year history of seropositive rheumatoid arthritis presenting with a generalised exacerbation of her arthritis, including marked synovial hypertrophy of both knees with a clinically detectable popliteal cyst on the left.

\section{Discussion}

The present study shows the ability of NMR tomography to demonstrate the presence of synovial inflammation, popliteal cysts, and a response to a potent anti-inflammatory agent. The small decrease in $T_{1}$ values in the untreated knees is probably due to the systemic effect of the intra-articular depot corticosteroid. A similar systemic effect has been observed with thermographic studies. ${ }^{12}$ Iodinated contrast media may cause systemic reactions when injected intravenously but have not previously been considered irritant when used intra-articularly. Iodide is not a strongly paramagnetic ion and therefore should not be expected significantly to alter the $T_{1}$ value of any fluid to which it is added. The small increase in $T_{1}$ values following arthrography suggests that iodinated contrast media are mildly irritant to the synovium in rheumatoid arthritis.

NMR tomography appears to be a safe, noninva- 
sive, and accurate method of assessing objectively the presence of and changes in popliteal cysts and synovial inflammation in rheumatoid arthritis. It is expected that further development of the technique will lead to improvement in the resolution of NMR images and enhance the accuracy of the localisation of $T_{1}$ values.

We thank Dr Linda Eastwood, Mr Glyn Johnson, Mr Tom Redpath, and Mr Robert Selbie, members of the NMR team of the University of Aberdeen, who through their work have produced the NMR imager used in this study, and also Professor J. R. Mallard for his help and encouragement. We are also grateful for the typing assistance of Moira M. Needler.

\section{References}

1 Moseley I. Recent developments in imaging techniques. Br Med J 1982; 284: 1141-4.

2 Smith F W, Hutchison J M S, Mallard J R, et al. Oesophageal carcinoma demonstrated by whole-body nuclear magnetic resonance imaging. $\mathrm{Br} \mathrm{Med} J$ 1981; 282: 510-2.

3 Smith F W, Mallard J R, Hutchison J M S, et al. Clinical application of nuclear magnetic resonance. Lancet 1981; i: 78-9.
4 Smith F W, Mallard J R, Reid A, Hutchison J M S. Nuclear magnetic resonance tomographic imaging in liver disease. Lancet 1981 ; i: $963-6$.

5 Smith F W, Hutchison J M S, Mallard J R, et al. Renal cyst or tumour? Differentiation by whole-body nuclear magnetic resonance imaging. Diag Imaging 1981; 50: 61-5.

6 Young I R, Hall A S, Pallis C A, Legg N J, Bydder G M, Steiner R E. Nuclear magnetic resonance imaging of the brain in multiple sclerosis. Lancet 1981; ii: 1062-6.

7 Smith F W. Clinical application of N.M.R. tomographic imaging. In: Witcofski R L, Karlstaedt N, Partain C L, eds. N.M.R. imaging. Winston-Salem: Bowman Gray School Of Medicine, 1982.

8 Mallard J R, Hutchinson J M S, Edelstein W A, Ling C R, Foster M A, Johnson G. In vivo N.M.R. imaging in medicine; the Aberdeen approach both physical and biological. Philos trans $R$ Soc Lond (Biol) 1980; 289: 519-33.

9 Hutchison J M S, Edelstein W A, Johnson G. A whole-body N.M.R. imaging machine.J Phys $(E)$ 1980; 13: 947-55.

10 Edelstein W A, Hutchison J M S, Johnson G, Redpath T W. Spin wrap N.M.R. imaging and applications to human whole-body imaging. Phys Med Biol 1980; 25: 751-6.

11 Edelstein W A, Hutchison J M S, Smith F W, Mallard J R, Johnson G, Redpath T W. Human whole-body N.M.R. tomographic imaging normal sections. Br J Radiol 1981; 54: 149-51.

12 Bird H A, Ring E F J, Bacon P A. A thermographic and clinical comparison of three intra-articular steroid preparations in rhe umatoid arthritis. Ann Rheum Dis 1979; 38: 36-9.

\section{Book review}

Le Pied en Pratique Rheumatologique: Pathologie Articularie. Eds. J. Claustre and L. Simon. Pp. 250. 245F. Masson: Paris. 1983.

This is perhaps the most comprehensive attempt yet to describe foot problems seen in rheumatology. Rheumatoid arthritis, diffuse connective tissue diseases, gout, and algodystrophies are among the conditions studied. Methods of examination, analysis, and surgical and orthotic treatments are also fully covered. Based on a conference held in Montpelier in 1982, the book inevitably contains repetitions, but also many good ideas, and it is worthy of a place in any rheumatology service seriously interested in problems of the feet. 